\title{
ENDOTRACHEAL INTUBATION FOR 31 DAYS IN A TETANUS PATIENT*
}

\author{
G. R. SEllery, M.D., DIP.ANAEs. (TOR.), F.R.C.P. (C) AND \\ B. L. BAKER, M.B., B.S.
}

IT HAS BEEN SUGGESTED by Bendixen and his colleagues ${ }^{1}$ as well as by many anaesthetists working in Intensive Care Units, that patients having artificial ventilation should not have an endotracheal tube in place longer than 48 hours. These patients would require a tracheotomy to prevent laryngeal complications caused by the endotracheal tube. Lindholm ${ }^{2}$ felt that the ulceration occurred on the medial sides of the arytenoid cartilages and the posterior subglottic area of the larynx. This damage could be reduced by using an endotracheal tube that put the least amount of pressure on these areas. He showed that the Portex Pvc tube when warmed to body temperature, by conforming to the anatomy of the upper airway put much less pressure on these areas than red rubber tubes. The other major factor was the reduction of laryngeal motor activity during the period of intubation.

The following report of a patient with tetanus demonstrates this principle in preventing laryngeal complications due to long term endotracheal intubation. This patient required ventilation and curarization to control his spasms. Normally a tracheostomy would have been done to facilitate artificial ventilation and suctioning. However in his case this was deemed to be almost impossible, due to the location of his injury and the amount of infection present.

Case Report: Mr.D. McM

This 46-year-old male sustained extensive gasoline burns to the anterior aspect of his neck and upper thorax on January 24, 1971 while working on his tractor on the farm. He was given emergency treatment at the local hospital, which consisted of sedation, dressings to the burned areas, penicillin, and tetanus toxoid.

On February 4th (11th day following accident) he began to complain of general malaise and slight dysphagia. He insisted that he had received a course of "antilock jaw shots" several years before. Within 24 hours his symptoms became more marked and he demonstrated classical signs of tetanus. Further treatment included 20,000 units of Tetabulin, the appropriate intravenous fluids, diazepam (Valium ${ }^{\circledR}$ ) $10 \mathrm{mg}$ intravenously q.3.h. and meperidine $50 \mathrm{mg}$ q.3.h., in an attempt to control his spasms.

During the following 48 hours, his general condition deteriorated and he developed marked respiratory difficulty with a risus sardonicus and frequent generalized convulsive movements of the trunk and limbs. He also became more confused and agitated.

On transfer to the Intensive Care Unit of our hospital he was isolated in a darkened room and attempts were made to minimize stimuli. He was semi-comatose, his respirations were shallow and rapid, but otherwise his vital signs were normal. Due to the respiratory failure indicated by clinical signs and blood gas changes,

\footnotetext{
*Department of Anaesthesia, University of Western Ontario and Victoria Hospital, London, Ontario.
} 
he was paralyzed and intubated with a Portex ${ }^{B}$ orotracheal tube and ventilated with a Bird Respirator. Because Succinylcholine could not be used due to the recent burn, curare was chosen as the relaxant. A Levine tube was passed to prevent acute gastric dilatation. For the control of his spasms he required $13.5 \mathrm{mg}$ of curare per hour which was administered by the Harvard Pump, and diazepam (Valium ${ }^{\circledR}$ ) was used as sedation in doses of 10 to $20 \mathrm{mg}$ every two to three hours.

The problem presented by this case was whether or not a tracheostomy should be done in a man who would require artificial ventilation for about three weeks. The burn extended over the anterior neck from the chin to the upper chest and was growing pseudomonas aeruginosa. It was felt that a tracheotomy through this area would be very dangerous (Figure 1). Consequently, we elected to manage this man with an endotracheal tube in place for as long as it was necessary. The tube was changed at weekly intervals and the otolaryngology consultant was present at the tube changes to examine the vocal cords for abnormalities.

The chest was kept clear by the usual routines of suctioning, humidification, physiotherapy, and intermittently hyperinflations except for one episode of atelectasis in the right base on February 21, 1971. Chest x-rays and blood gases were done almost daily to follow this aspect of the patient's course.

A complication that did occur was related to his hyperalimentation regimen administered through the central venous pressure line. This regimen of hyprotigen in 50 per cent glucose was started on February 9 th, in an attempt to prevent wasting from protein loss at the burn site. The serum sodium gradually rose to $177 \mathrm{mEq} / \mathrm{L}$ and his blood sugar went up to $894 \mathrm{mg}$ per cent. This occurred very suddenly and he became comatose and hypotensive for a short period. The diagnosis at this time was hyperosmolar coma believed to be precipitated by the osmotic diuretic effect of the glucose in the hyperalimentation regimen. Another factor may have been the reduction in metabolism due to muscle paralysis due to the use of curare. The patient recovered from this with the use of insulin, potassium supplements and low sodium solutions.

During the following week the curare requirements decreased so that by February 26 th his spasms had almost disappeared and the curare was discontinued. It was noted that in the mornings his respiratory tract seemed to be full of secretions and that he had a low $\mathrm{PaO}_{2}$, whereas in the afternoon he was much improved. It was realized that the night nurse felt that the tetanus patient should be left undisturbed in a quiet room, so physiotherapy and suctioning of the airway were reduced during the night, resulting in this problem.

On February 26th his endotracheal tube was again changed and no definite pathological change was visualized in the larynx other than slight redness of the cords. There was no evidence of mucosal lesions which are supposed to precede granuloma formation and fibrous scarring. Weaning from the respirator was started on March 1st. This took a long time but muscle power gradually increased and his vital capacity was felt to be adequate for him to be extubated. Following a short course of solucortef to reduce swelling in the airway, he was extubated on March 9 th. However, that evening his respiratory rate rose along with his heart rate and his $\mathrm{Po}_{2}$ fell. A chest $\mathrm{x}$-ray showed right lower lobe atelectasis. He was taken to the operating room and a bronchoscopy was done under general anaesthesia as described by Spoerel. ${ }^{4}$ The right lower lobe bronchus was suctioned and reinflated. 


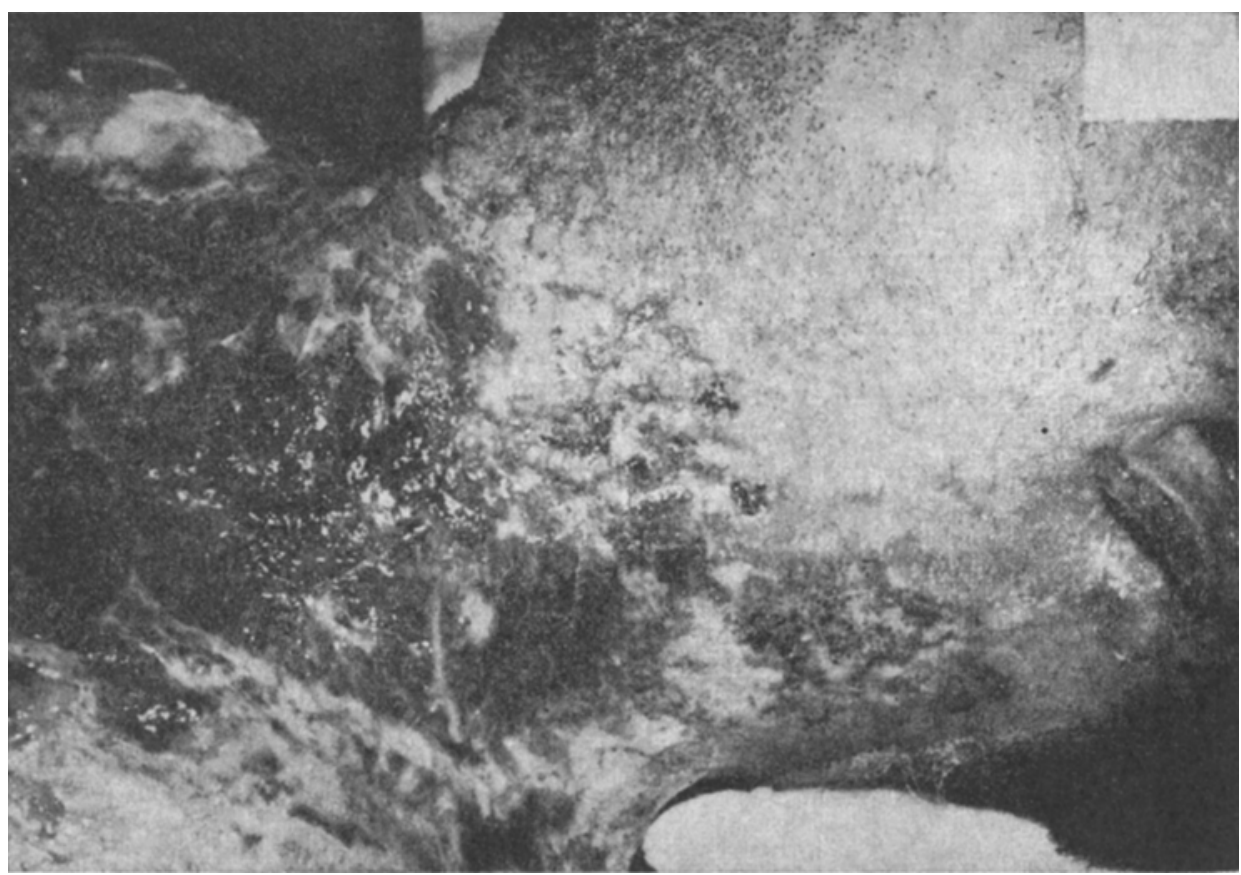

Figure 1. Burns of anterior neck infected with pseudomonas aeruginosa.

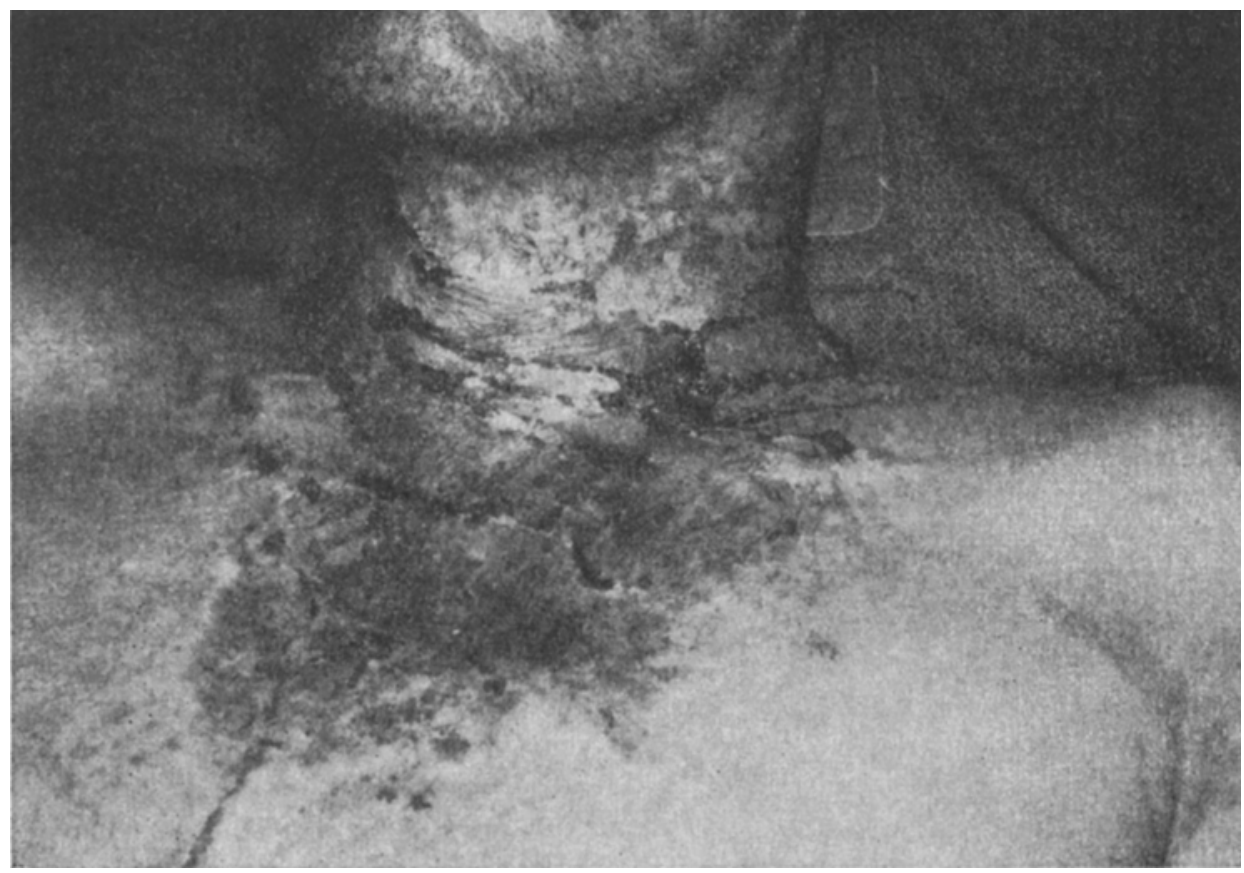

Figure 2. Burns of anterior neck following skin grafts. 
A granulomatous lesion, $1 \mathrm{~cm}$ in diameter was also noted in the right main bronchus and was presumably caused by repeated suctioning.

Following extubation his cough was harsh in sound but was quite productive. His voice initially was only a whisper but after a few days he could communicate with a hoarse voice. The patient was transferred to the surgical floor with a hoarse voice but no evidence of stridor. His burns required skin grafting and further treatment (Figure 2).

On discharge from this hospital, the patient had some mild hoarseness but otherwise no problems with his larynx or trachea. He was seen in the Outpatient Clinic on April 30, 1971 about seven weeks following extubation, by the otolaryngology consultant. At that time the voice was entirely normal, there was no dyspnoea and the cords appeared normal on indirect laryngoscopy.

\section{Discussion}

This case report demonstrates the possibility of managing a patient on a respirator with an endotracheal tube in place for prolonged periods. When a tracheotomy is deemed to be a serious risk, as was the case in this patient, this regimen is reasonable. Provided that expert management of the endotracheal tube including suctioning and humidification is carried out, as well as ensuring that the tube used conforms to the anatomy of the patient's airway, the risk of complications is reduced. In this case the tube was changed at weekly intervals and the larynx was inspected at these tube changes by the otolaryngology consultant. We were prepared in this case to perform surgery as necessary to correct the very serious laryngeal complications that could have occurred.

This case also raises the question of the possibility of using an endotracheal tube for more prolonged periods than in the past, as this would rule out the chance of stenosis at the tracheostomy stoma. It is important to note, however, that this patient was paralyzed for most of his course and well sedated, so that there was almost no movement of the tube in the larynx, which would have increased the chance of complications.

\section{SUMMARY}

A patient with tetanus in whom a tracheotomy was deemed contraindicated was managed for 31 days of artificial ventilation with an endotracheal tube in place, with no permanent sequelae.

\section{RÉSUMÉ}

Un malade souffrant de tétanos chez qui une trachéotomie a été jugée contre indiquée a été soumis durant 31 jours à une ventilation artificielle à travers un tube endotrachéal sans sequelle permanente.

\section{REFERENCES}

1. Bendixen, H. H.; Egbert, L. D.; Hedley-Whtte, J.; Laver, M. B.; \& Pontoppidan, H. Respiratory Care. The C. V. Mosby Company, St. Louis, 1965.

2. Lindholm, C. E. Prolonged Endotracheal Intubation. Acta Anaesth. Scandinav., 33 (1969).

3. Cole, L. \& Youngman, H. The Treatment of Tetanus. Lancet, 1: 1017-1019 (1969).

4. Spoerel, W. E. Ventilation Through an Open Bronchoscope (Preliminary Report). Canad. Anaesth. Soc. J., 16: 61 (1969). 